\title{
The experimental determination of the relationship between the energising time of the common rail injector and the set fuel quantity and rail pressure
}

\author{
Dariusz Pietras, ${ }^{1, *}$, Tomasz Knefel $^{1}$, and Mateusz Satława ${ }^{1}$ \\ ${ }^{1}$ University of Bielsko-Biala, Faculty of Mechanical Engineering and Computer Science, ul. Willowa 2, 43-309 Bielsko-Biala, Poland
}

\begin{abstract}
The article discusses the issue of experimentally determining the relationship between the energising time of the common rail electromagnetic injector and the set fuel quantity and rail pressure. Experimental studies according to the assumed methodology were made on a test bench enabling the dynamic flow rate measurement of the injector. The fuel system mounted on the test bench was controlled by the laboratory $\mathrm{CI}$ engine control unit based on the original concept of one of the authors of the article. The results of the experimental studies have made it possible to determine many of the characteristics of the fuel flow rate depending on the specified rail pressure and the energising time of the injector. An analysis was then performed followed by extrapolation of the obtained results. The data obtained from these analyses are the basis for the development of the energising time control algorithm based on a set fuel quantity and rail pressure.
\end{abstract}

\section{Introduction}

The authors of this paper have been working for many years in a research facility that specializes in the issues related to the selection and optimization of the engine control process parameters for both gasoline and diesel engines [1-3].

The current state of knowledge suggests that the number of injections per one engine work cycle, the amounts of particular fuel dose parts, and the delay or advance angles of the beginning of injection of particular parts, i.e. in general, the overall volume-time characteristics of the fuel injection process significantly affect the heat release and, consequently, the engine performance, as well as the contents of harmful substances in the exhaust gas, including solid particles (mainly soot), and the noise generated by the engine in operation [4-7].

Fuel dose division also applies to issues related to the mathematical modeling of the engine work cycle process and the mathematical modeling of fuel supply systems for gasoline and diesel engines [8-10].

Factory-setting controllers developed for specific engine models often do not allow for easy modification of the engine performance parameters. Due to its complicated construction, the number of registered and operational parameters is up to 3000 and interdependencies between them make it impossible to use them in scientific research.

Thus, it became necessary to design and execute, yet another, less complex system driver in terms of the interrelation of control parameters that are relevant when the engine is mounted into the vehicle. The main feature of the newly developed driver was the ability to enable dynamic engine operation on the engine dynamometer, because the driver structure is based on array algorithms [2].

The basic parameter in the control of modern diesel engines equipped with common rail fuel supply systems is the driver of the injector energising time (ET) (coil supply). Important in this issue is to know the relationship between the energising time and the real fuel injection process $[8,11,12]$

For the driver development design assumptions, it was assumed that the control of this parameter is to be carried out on the basis of the set fuel quantity $(Q)$ and rail pressure $\left(p_{\text {rail }}\right)$. The driver based on the programmed algorithm will determine the energising time.

Conducting research based on the developed methodology was meant to provide the basis for the development of an algorithm controlling the injector energising time based on the set fuel dose and the rail pressure.

\section{Methodology}

\subsection{Test stand}

Experimental research was carried out in the laboratory of the Department of Combustion Engines and Vehicles of the University of Bielsko-Biala. The test bench power supply is electronically controlled using a test stand based on the Star 8 test stand [8].

On the test stand, a common-rail power supply system was installed for the 1.3 SDE engine.

*Corresponding author: pietras@ath.bielsko.pl 

using:

Precise electronic control of the test stand was done

- Th

-phase AC motor with an inverter, driving the test stand spindle. It enables high torque at low speeds and also stabilizes the rotational speed.

- Fuel heating system. It allows for setting the required temperature and stabilize it when it is reached.

- The control system of a set number of injection injections that works in conjunction with the electromagnetic displacement actuator and with a reluctant rotational speed sensor. The value of the set injection cycle number is used to determine the specific dosage of the fuel.

The test stand is shown in Fig. 1 [13]. The injection system was controlled by a laboratory universal diesel engine driver. The driver was created within the framework of the research project No. 5178/B/T02/2011/40 financed by the National Science Center according to the original concept of the project manager. In addition to the CI engine control function on research test stands, the driver also enables the testing of common rail systems on appropriate test stands.

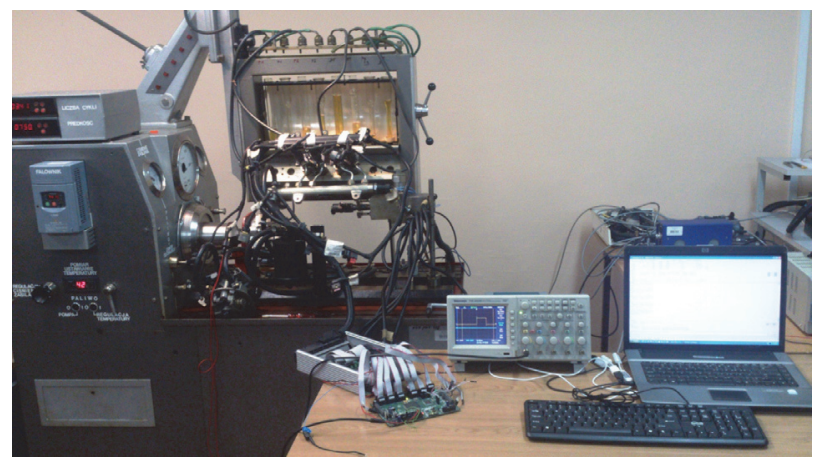

Fig. 1. View of test stand [13].

\subsection{Research plan}

The study consisted of measuring the fuel mass injected into the burette by each of the four injectors for set values of energising time, the rail pressure and the set number of injection. The range of injector energising time and rail pressure changes are shown in Tab. 1. The number of injection was set so that the minimum injection volume was not less than $3 \mathrm{~cm}^{3}$. The number of injections was 250, 500, and 1000 in the test. The value of 1000 was related to the short time of the injector energising time and the low rail pressure, while 250 injections per measurement test were carried out for long periods of injector energising time and high rail pressure. In the research description, as well as in the rest of the article, the fuel rail pressure values were reported in bars, because this unit is most commonly used in the technical descriptions of the injector manufacturers and in other papers in this subject. On test stand to fueled the injection equipment has been used the diesel fuel. Increasingly, CI engines with common rail systems are fueled by bio-fuels [14-16]. The results obtained on diesel should be consistent for other fuels because of assumptions about the parameters of physical properties of bio-fuels, although in some engine states (fuel temperature) the results may be different [17].

The fuel weight was measured using a RADWAG WPE 600 precision scale.

Table 1. Range of changes in set parameters $(E T[\mu \mathrm{s}])$

\begin{tabular}{|c|c|c|c|c|c|c|c|c|c|c|}
\hline \multicolumn{10}{|c|}{$p_{\text {rail }}[\mathrm{bar}]$} \\
\hline 270 & 400 & 500 & 600 & 700 & 800 & 900 & 1000 & 1100 & 1200 & 1300 \\
\hline 250 & 250 & 250 & 250 & 250 & 250 & 250 & 250 & 250 & 250 & 250 \\
300 & 300 & 300 & 300 & 300 & 300 & 300 & 300 & 300 & 300 & 300 \\
400 & 400 & 400 & 400 & 400 & 400 & 400 & 400 & 400 & 400 & 400 \\
500 & 500 & 500 & 500 & 500 & 500 & 500 & 500 & 500 & 500 & 500 \\
600 & 600 & 600 & 600 & 600 & 600 & 600 & 600 & 600 & 600 & 600 \\
700 & 700 & 700 & 700 & 700 & 700 & 700 & 700 & 700 & 700 & \\
& 800 & 800 & 800 & 800 & 800 & 800 & 800 & 800 & 800 & \\
& & & 900 & 900 & 900 & 900 & 900 & 900 & & \\
& & & & & 1000 & 1000 & 1000 & & & \\
\hline
\end{tabular}

Each of the 77 research points was performed in accordance with the following plan:

- preparation of the test stand: maintaining the set fuel temperature, draining of the burettes,

- entering the required $E T$ and $p_{\text {rail }}$ in the driver software,

- setting the number of injections,

- measurement of the mass of empty burettes,

- performing the test,

- recording the diesel fuel temperature,

- measuring the weight of the burettes with fuel.

\section{Research results and their analysis}

Research was carried out based on the methodology outlined in Section 2.2. Taking into account the number of injections in each test, the mass of fuel per injection was determined. The methodology for presenting the results on the charts would be the similar to the research work of other authors [18, 19].

The graphical results are shown in Fig. 2 to 6 for selected pressures: 250, 500, 700, 900 and 1300 bar. For graphs with a green background, a maximum value for the fuel mass axis of $45 \mathrm{mg} /$ cycle was used and a maximum value for the injector energising time axis was $1050 \mu \mathrm{s}$. In this way, it is easier to compare the values of the mass increase for all the pressures tested. Furthermore, two additional graphs for a cylinder pressure of 267 and 500 bar are also shown to better illustrate the difference in fuel mass for individual injectors.

For a storage rail pressure of 267 bar (Fig. 2), the mass values of fuel injected into the burettes are small. The first and second injectors did not inject the fuel into the burettes at all. The maximum injection value is obtained for injector 4 . It should be added that for the tested injection system, the rail pressure of 270 bar corresponds only to the idling engine operation. 

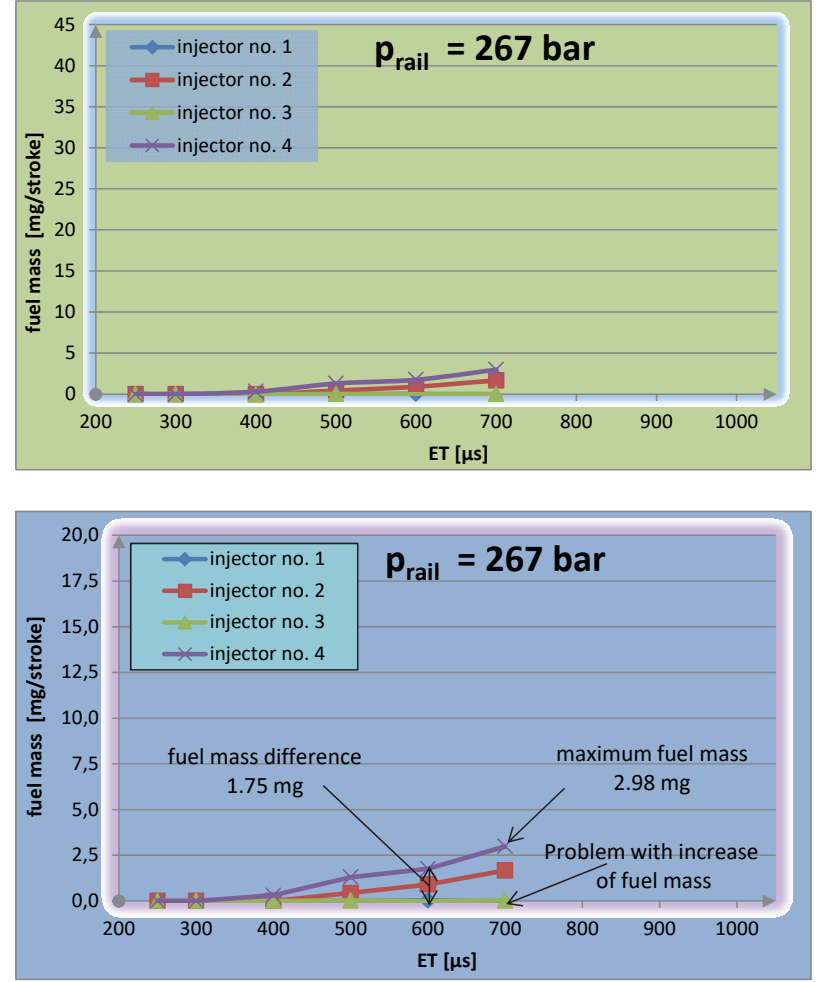

Fig. 2. Change of fuel mass as a function of energising time for rail pressure equal 267 bar.
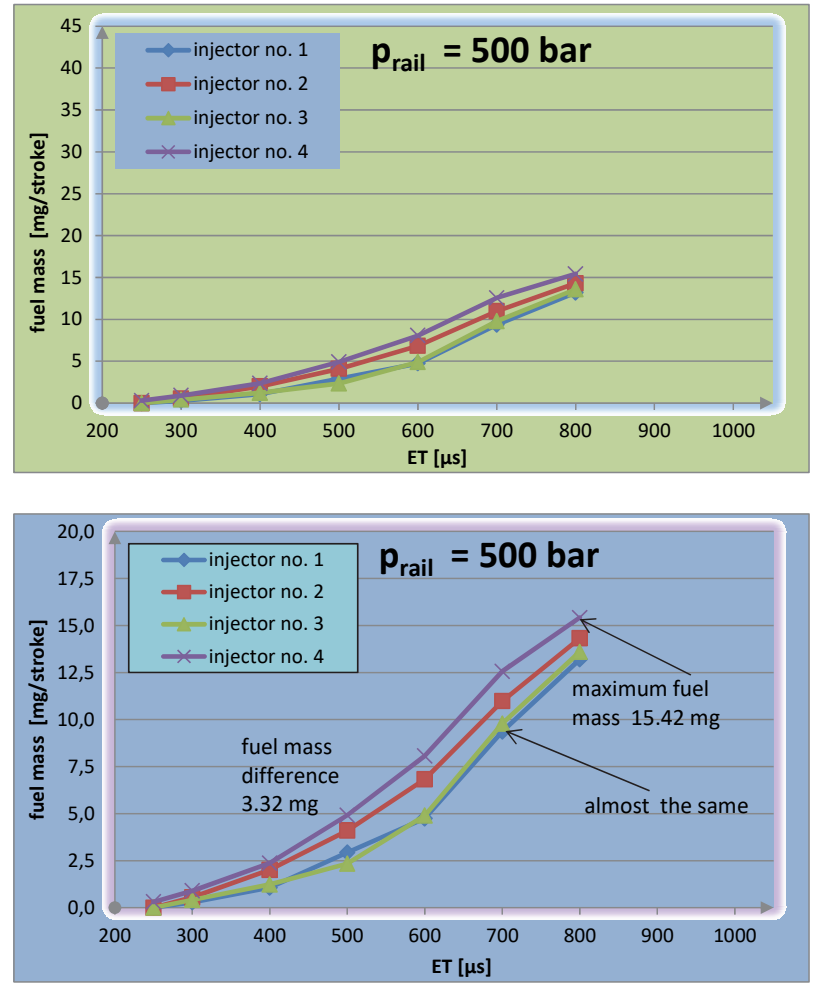

Fig. 3. Change of fuel mass as a function of energising time for rail pressure equal 500 bar.

Fig. 3 shows the change of the injected fuel mass as a function of the energising time and the rail pressure at 500 bar. Compared to the case discussed above, weight increase was observed for each of the investigated injectors. Just like before, the maximum injected mass of the fuel in the burettes occurred for injector 4. The functions for injectors 1 and 3 practically overlapped, but their values diverged from the values obtained for injectors 2 and 4 . As before, the linear nature of the change in fuel mass can be observed.

Fig. 4, 5 and 6 show the change in weight of the injected fuel as a function of the energising time for the rail pressure of 700, 900 and 1300 bar, respectively.

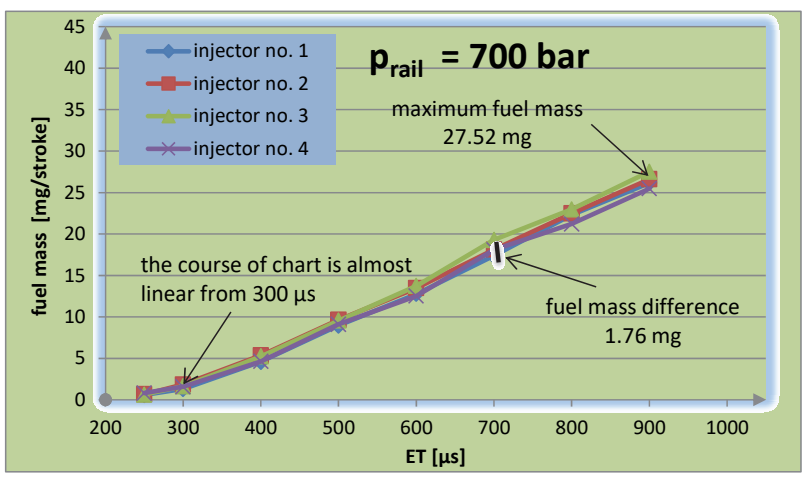

Fig. 4. Change of fuel mass as a function of energising time for rail pressure equal 700 bar.

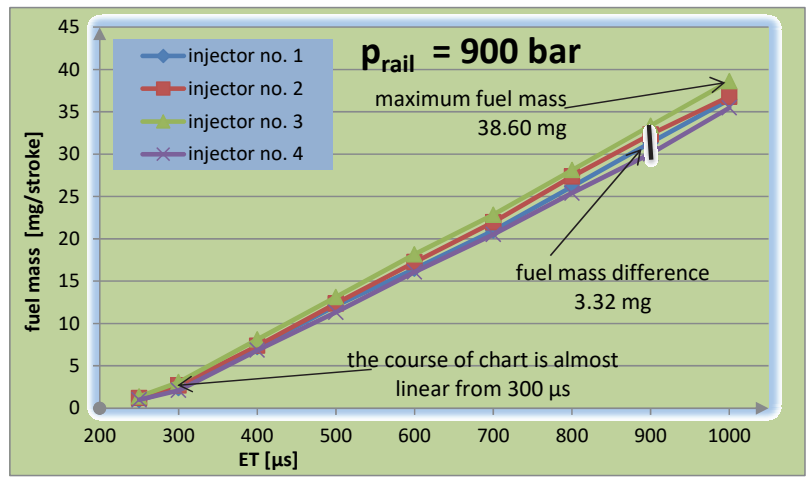

Fig. 5. Change of fuel mass as a function of energising time for rail pressure equal 900 bar.

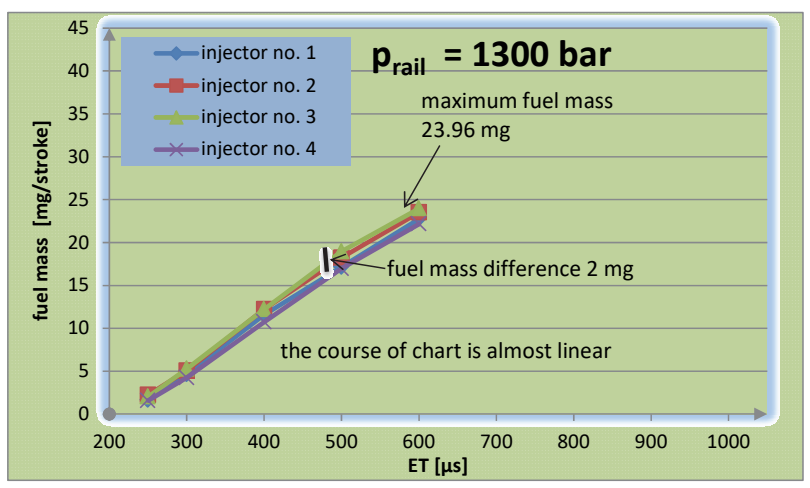

Fig. 6. Change of fuel mass as a function of energising time for rail pressure equal 1300 bar.

The injected fuel mass relation with the energising time shown in the three figures has a linear character even at the shortest energising times. At the same time, the differences in the injected fuel mass between different injectors are small or even negligible. 


\section{Determination of fuel quantity as a function of ET and $p_{\text {rail }}$}

Based on the measurement of the fuel temperature at each measurement point and the relation of the test fuel density as a function of temperature, the volume of fuel injected was determined. The waveforms shown in Fig. 7-9 show the averaged fuel injection results for injectors 2 and 4. Due to the large discrepancies in the results for injectors 1 and 3, especially for low pressures, they were omitted in further analyzes. Figure 7 shows the actual fuel dosage as a function of the injector's energising time for the individual rail pressures. The functions are linear, which is directly tied to the results of the individual pressure tests discussed in Chapter 2. The nature of the variation in fuel dosage from energising times correlates with the literature data particularly for high fuel rail pressure values.

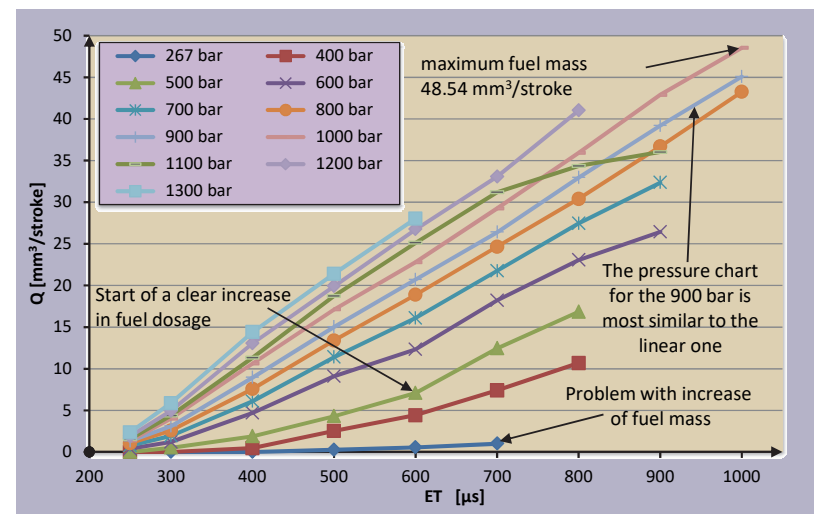

Fig. 7. Change of fuel quantity as a function of energising time for different rail pressure.

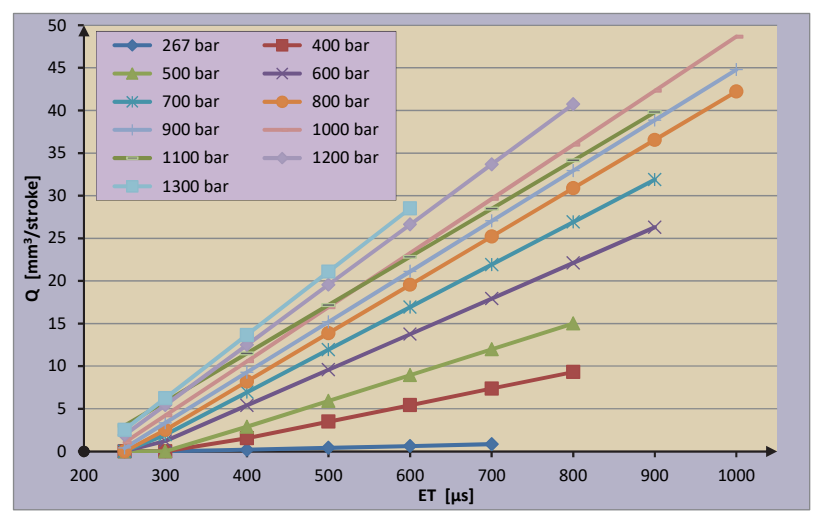

Fig. 8. The effect of the linear regression on fuel quantity as a function of energising time for different rail pressure.

For a rail pressure of 1100 bar, there is a divergence from the linear nature of the fuel dose increase starting at the energising time of $700 \mu \mathrm{s}$. Most likely this is due to technical problems that occurred during this measurement. These were related to the maintenance of the pressure in the supply system, which has been noted as significant after the last test at a pressure of 1100 bar.

The next step of the analysis was the linear regression of the obtained results shown in Fig. 7. The effect of the regression process is shown in Fig. 8. The linear results obtained with high accuracy corresponded to the real results.

The fuel level is clearly higher for higher fuel pressure values in the rail. The only deviation from this character of changes is the fuel dose at a rail pressure of $1100 \mathrm{bar}$, which is due to the reasons described above.

\section{Development of data for the energising time control algorithm}

As mentioned in the introduction, the purpose of the research and the analyses discussed above was to determine the energising time relation between the common rail injector control and the pre-set dose and the rail fuel pressure. To achieve the intended effect, after performing a linear regression of the results further analysis was required. This problem was realized through the extrapolation of linear regression results (Fig. 9). Straight lines marked in color correspond to values in the measuring range. The functions shown in black are the result of extrapolation. Through this method the values of the energising time dependence from the set fuel dose were determined in a wider range of fuel dose variation than those obtained in the performed experimental studies.

Taking the assumptions that the time ET is to be determined from the set fuel dose into consideration, the axes are further inverted relative to the graph 8 so that the graph represents the dependence of the injector energising time on the fuel dose for the different rail pressure values.

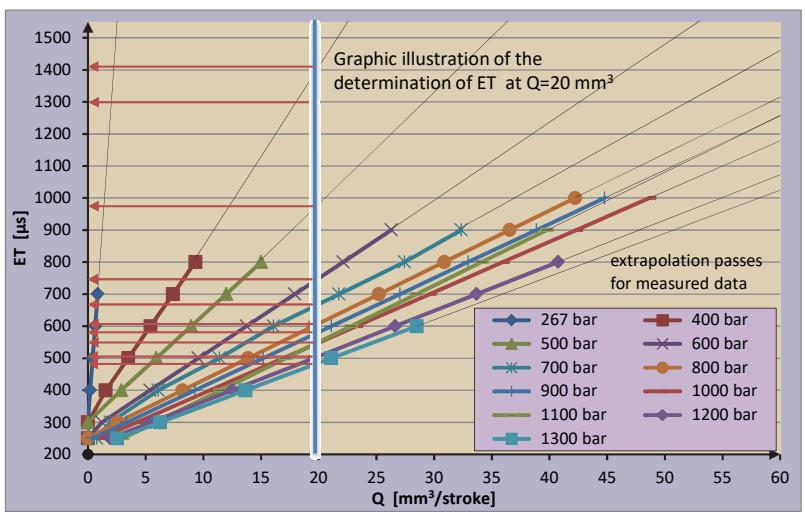

Fig. 9. Graphic illustration of the determination $E T$ for different values of the rail pressure and the prescribed fuel quantity.

Figure 9 shows a graphical representation of the energising time control method for a test fuel dose of $20 \mathrm{~mm}^{3}$ and different rail pressure values. It can be observed how the injector ET changes depending on the rail pressure. The higher the rail pressure, the shorter the opening time of the injector. However, the differences between the injector energising time are different for the various fuel pressures in the rail. For example, the difference between 500 and 600 bar is approximately $231 \mu \mathrm{s}$, whereas for 1200 and 1300 bar is only about $21 \mu \mathrm{s}$. 
Given that the relationships shown in Figure 9 are linear, it is possible to precisely determine the energizing time for the individual fuel doses and the various rail pressures. The values of the determined energising times are shown in Table 2 in the form of an array algorithm.

Table 2. Parameters of the control algorithm for the energising time.

\begin{tabular}{|c|c|c|c|c|c|c|c|c|c|c|}
\hline & \multicolumn{10}{|c|}{$p_{\text {rail }}[\mathrm{bar}]$} \\
\hline $\begin{array}{c}\mathrm{Q} \\
{\left[\mathrm{mm}^{3} /\right.} \\
\text { stroke] }\end{array}$ & \& & \& & 8 & 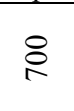 & \& & \&ু & 8 & $\stackrel{\varrho}{\varrho}$ & 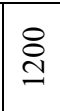 & \& \\
\hline 0 & 0 & 0 & 0 & 0 & 0 & 0 & 0 & 0 & 0 & 0 \\
\hline 1 & 346 & 319 & 288 & 282 & 271 & 260 & 249 & 215 & 237 & 22 \\
\hline 2 & 402 & 354 & 312 & 302 & 289 & 277 & 265 & 232 & 251 & 24 \\
\hline 3 & 458 & 89 & 37 & 322 & 307 & 294 & 281 & 250 & 265 & 25 \\
\hline 4 & 514 & 424 & 361 & 342 & 324 & 311 & 297 & 268 & 280 & 27 \\
\hline 5 & 570 & 459 & 385 & 362 & 342 & 328 & 312 & 285 & 294 & 28 \\
\hline 6 & 626 & 494 & 410 & 382 & 360 & 345 & 328 & 303 & 308 & 29 \\
\hline 7 & 682 & 528 & 434 & 402 & 377 & 362 & 344 & 321 & 322 & 31 \\
\hline 8 & 738 & 563 & 458 & 422 & 395 & 379 & 360 & 338 & 336 & 3 \\
\hline 9 & 794 & 598 & 483 & 442 & 413 & 395 & 375 & 356 & 350 & 33 \\
\hline 10 & 850 & 633 & 507 & 462 & 431 & 412 & 391 & 374 & 365 & 35 \\
\hline 15 & 1130 & 807 & 628 & 562 & 519 & 497 & 470 & 462 & 435 & 41 \\
\hline 20 & 1409 & 981 & 750 & 662 & 608 & 581 & 549 & 550 & 506 & 48 \\
\hline 25 & 1689 & 1156 & 872 & 761 & 696 & 666 & 627 & 639 & 577 & 55 \\
\hline 30 & 1969 & 1330 & 993 & 861 & 784 & 750 & 706 & 727 & 648 & 62 \\
\hline 35 & 2249 & 1504 & 1115 & 961 & 873 & 835 & 785 & 815 & 719 & 68 \\
\hline 40 & 2528 & 1678 & 1236 & 1061 & 961 & 919 & 864 & 904 & 790 & 7 \\
\hline
\end{tabular}

The algorithm specifies all injector energising times as a function of the set fuel dose and rail pressure. However, not all the values are present in engine control. For example, high fuel dose injection is not performed at very low pressures. To illustrate this case, a graph limiting the maximum injector energising time to 1100 $\mu \mathrm{s}$ was made. Also, measurements for the fuel supply rail pressure value of 267 bar was omitted intentionally because, as previously mentioned, it only occurs for the idle speed.

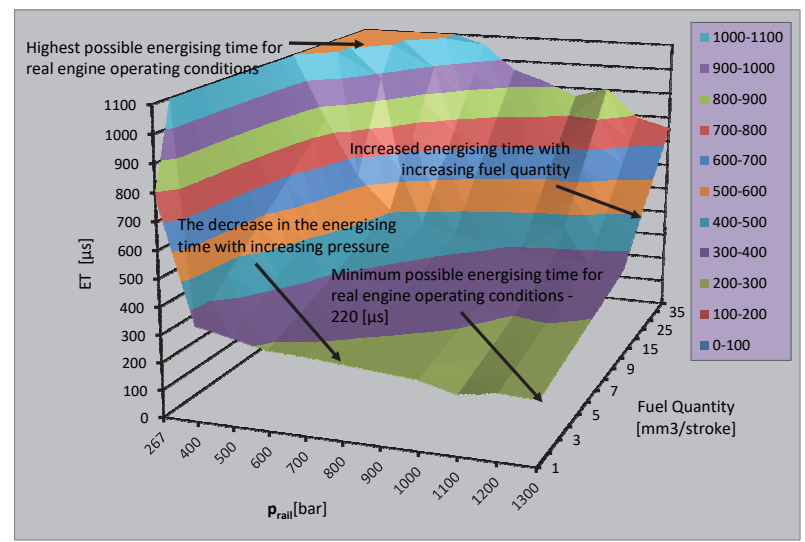

Fig. 10. Graphic interpretation of determining the energising time based on parameters contained in the algorithm shown in Table 2.

\section{Conclusions}

Planned and performed experimental studies as well as their further analysis have proven useful. One of the main goals set out in the development of the concept of laboratory operation of a universal diesel engine driver, i.e. determining the relationship between the set fuel dose, the fuel pressure in the cylinder, and the injector energising time.

By analyzing the research results (Fig. 7), a reduction in the fuel dose increase relative to the increase in injection pressure for the various injection energising times. This may be due to the reduction in the active cross section of the fuel stream that flows through the spray nozzle openings while increasing the injection pressure for the same time as the injector's energising time.

Divergence in the results for individual injectors, especially for short energising times and low fuel pressure values in the rail may be caused by three different reasons. The first is measurement errors that become very significant when measuring very small doses of fuel. The second reason is probably the lack of any adjustments in the timing of the individual injectors applied during the test. At the same time, this confirms the correctness of the factory-specified injector control corrections included in the original software codes. The injectors used in the experiment were not brand-new. There could therefore be variations in dosage resulting from the operational wear on the hydraulic and electrical parts of the injectors. This could be the third cause of injector dosage inaccuracies for small energising times and low rail fuel pressures.

At the same time, the authors acknowledge that these considerations concerned studies corresponding to a single injection dose. For engine tests, the fuel injection algorithms will also be programmed for two, three, or even five injection steps in the driver algorithm. There may be a discrepancy between the planned and the actual injected fuel dose resulting from the injectors not completely closing at short dwell times between the various injection steps [20]. The injector solenoid coil is an inertial element, so the current continues to flow for a time after the supply voltage has disappeared.

The publication has been produced as part of the research project no. 5178/B/T02/2011/40 financed from the resources of the National Science Centre.

\section{References}

1. T. Knefel, Maintenance and Reliability 14, 42-53 (2012)

2. Z. Stelmasiak, T. Knefel, J. Larisch, Pomiary, Automatyka, Kontrola 56, 217-220 (2010)

3. Z. Stelmasiak, T. Knefel, J. Larisch, Combustion Engines, 2007-SC2, 173-180 (2007)

4. I. Pielecha, W. Cieslik, Journal of Thermal Analysis and Calorimetry 126, 815-827 (2016), DOI: 10.1007/s10973-016-5544-1 
5. L.J. Kapusta, I. Pielecha, K. Wisłocki, A. Teodorczyk, Journal of Thermal Analysis and Calorimetry 123, 819-828 (2016), DOI: 10.1007/s10973-015-4927-z

6. I. Pielecha, K. Wislocki, P. Borowski, W. Cieslik, Journal of Thermal Analysis and Calorimetry 122, 473-485 (2015), DOI: 10.1007/s10973-015-4735-5

7. D. Pietras, Polish Maritime Research 3, 3-12 (2016), DOI: 10.1515/pomr-2016-0032

8. T. Knefel, Scientific dissertations (Scientific Publishing University of Bielsko-Biala, 2013)

9. I. Pielecha, International Journal of Automotive Technology 15, 47-55 (2014), DOI: 10.1007/s12239-014-0005-y

10. I. Pielecha, P. Borowski, J. Czajka, K. Wislocki, J. Kazmierowski, Journal of Thermal Analysis and Calorimetry 119, 695-703 (2015), DOI: 10.1007/s10973-014-4139-y

11. T. Knefel, J. Nowakowski, Combustion Engines 169, 113-119 (2017), DOI: 10.19206/CE-2017-220

12. M. Skowron, I. Pielecha, K. Wislocki, IOP Conference Series-Materials Science and Engineering 148, UNSP 012085 (2016), DOI: 10.1088/1757-899X/148/1/012085

13. M. Satlawa, Archive of diploma theses (University of Bielsko Biala, 2017)

14. W. Karpiuk, T. Borowczyk, M. Idzior, R. Smolec, 2016 International Conference on Sustainable Energy, Environment and Information Engineering 16-22 (2016)

15. W. Karpiuk, R. Smolec, M. Idzior, 2016 International Conference on Sustainable Energy, Environment and Information Engineering 37-43 (2016)

16. J. Merkisz, M. Idzior, P. Lijewski, P. Fuc, W. Karpiuk, Proceedings of the Ninth Asia-Pacific International Symposium on Combustion and Energy Utilization 352-356 (2008)

17. A. Rybak, J. Hunicz, P. Krzaczek, Combustion Engines 171, 39-43 (2017), DOI: 10.19206/CE2017-407

18. W. Busz, A. Walaszyk, Combustion Engines 162, 978-981 (2015)

19. T. Osipowicz, K.F. Abramek, T. Stoeck, Combustion Engines 162, 688-694 (2015)

20. M. Reza Herfatmanesh, Z. Peng, A. Ihracska, Y. Lin, L. Lu, C. Zhang, Advances in Mechanical Engineering 8, $\quad 1-8 \quad$ (2016), $\quad$ DOI: $10.1177 / 1687814016648246$ 